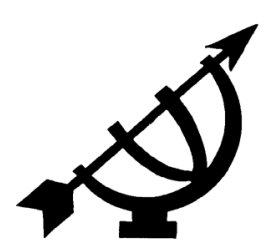

\title{
De strijd om de richting van de Westerse cultuur
}

\author{
E. Schuurman \\ Emeritus: Reformatorische Wijsbegeerte \\ Universiteit van Delft \\ DELFT \\ Email: eschuurman37@hetnet.nl
}

Abstract

\section{The struggle around the direction of Western culture}

Herbert Marcuse is the most important representative of the cultural revolution of the sixties of the twentieth century. He represents resistance against the scientific-technological ideal of the Enlightenment. His ideal of freedom has, nevertheless, the same roots.

Since the Enlightenment Western culture has been characterised by a struggle between the freedom ideal and the scientific-technological control ideal. To lessen the tension we need a cultural transformation. Therefore we need an enlightenment of the Enlightenment. In the old cultural paradigm, nature is seen as lifeless and, given that framework, is exploited by unbridled manipulation. Today we see how the technologicaleconomic development threatens "life" itself, to the point of destroying it. A responsible cultural development summons a representation of culture that depicts earth as a garden tended by humans. The garden has to be developed in the perspective of a city garden, where righteousness, love and therefore protecting life are the main principles. To follow such guidelines implies a spiritual and philosophical struggle in the direction of a transformation of Western culture.

\section{Samenvatting}

\section{De strijd om de richting van de Westerse cultuur}

Herbert Marcuse is de belangrijkste vertegenwoordiger van de culturele revolutie van de twintigste eeuw. Hij vertegenwoordigt de weerstand in de Westerse cultuur tegen het wetenschap- 
pelijk-technisch ideaal van de Verlichting. Zijn vrijheidsideaal heeft niettemin dezelfde wortels.

Sinds de Verlichting wordt de Westerse cultuur beheerst door de strijd tussen deze twee idealen. Om de strijd te verminderen en de spanning in de cultuur te laten afnemen, is een transformatie van de cultuur noodzakelijk. Daarvoor hebben we een verlichting van de Verlichting nodig. In het oude cultuurparadigma wordt de natuur als levenloos gezien en, gezien dat ethisch kader, uitgebuit door grenzenloze manipulatie. Vandaag zien we hoe de technisch-economische ontwikkeling op grote schaal het "leven" bedreigt en vaak al vernietigt. Een verantwoorde cultuurontwikkeling vertegenwoordigt een cultuurparadigma dat de aarde in ontwikkeling ziet naar een grote tuinstad in het perspectief van gerechtigheid en liefde. In die toekomstige cultuurontwikkeling moeten economie en technologie het leven dienen. In dat perspectief de cultuur ontwikkelen, betekent een geestelijke en filosofische strijd in de richting van een transformatie van de materialistische Westerse cultuur.

\section{Culturele revolutie}

Er wordt nog steeds veel gesproken over wat er in de zestiger jaren in de Westerse wereld gebeurde. Dat was de tijd dat Bennie van der Walt en ik samen studeerden aan de Vrije Universiteit van Amsterdam. Het was de tijd van wat we een culturele revolutie noemen.

In 1967 gaf ik voor het eerst colleges wijsbegeerte binnen het kader van de Wijsgerige Vorming aan de Vrije Universiteit. In de Centrale Interfaculteit was ik vanaf die tijd ook voorzitter van de commissie die zich met organisatie en inhoud van dat onderwijs binnen alle faculteiten bezighield.

Tot 1968 was het min of meer vanzelfsprekend dat dit onderwijs gestempeld werd door de inbreng van reformatorische filosofen als Dooyeweerd, Vollenhoven, Van Riessen en Zuidema. Die vanzelfsprekendheid werd sinds 1968 steeds meer aangevochten. De oorzaak daarvan was niet in de eerste plaats dat het merendeel van de studenten niet meer van christelijke huize was, al speelde dat wel mee. Ook van buitenaf was er sprake van veel invloed. Wereldwijd was sinds 1968 de studentengeneratie in verzet gekomen tegen de hoofdstroom in de cultuur. Niet voor niets wordt 1968 dan ook wel het jaar van de revolutionaire studenten genoemd. De grote leider van het studentenverzet was de filosoof Herbert Marcuse. Zijn boeken, Eros and civilization en One dimensional man, werden door vele studenten met instemming gelezen. Ook voegden ze de daad 
bij zijn filosofisch woord: de cultuur moest daadwerkelijk revolutionair veranderen.

Studenten van de Vrije Universiteit namen onder invloed van deze beweging geen genoegen meer met de gangbare wijsgerige vorming, die christelijk geïnspireerd was. Voortdurend waren er conflicten over de inhoud en het aantal van de colleges. En voortdurend moesten er aanpassingen plaats vinden. Het gedrag van studenten in die tijd was allesbehalve aangepast. Ze kwamen op klompen naar de colleges en daagden de docenten voortdurend uit en gaven er blijk van alles te willen vernieuwen. Daaruit bleek dat ze hun leermeester Marcuse trouw wilden zijn.

Nú kennen vele studenten Marcuse zelfs niet meer van naam, maar zijn invloed is sinds die tijd in denken, doen en laten van velen in de universiteit en daarbuiten toegenomen. Vele veranderingen en de gevolgen daarvan gaan terug op wat er ruim 40 jaar geleden in de Westerse cultuur plaats vond.

Laten we eens terug kijken. Ik zal proberen duidelijk te maken dat Marcuse in de lijn van de Verlichting zich enerzijds er tegen verzet en anderzijds die Verlichting ook radicaliseert.

\section{Herbert Marcuse}

Wie was Marcuse? Hij promoveerde in 1932 op de filosoof Hegel bij de filosoof Martin Heidegger. Heidegger wordt wel de belangrijkste filosoof van de twintigste eeuw genoemd. Hij was als existentialist een kritisch bezinnend denker. Een hoofdlijn in zijn filosofie is zijn visie op de technologie. Door die technologie is de mens van het zijn, van de natuur, en van zijn eigelijke wezen - zijn existentie vervreemd. Heidegger blijft volledig het antwoord schuldig op de vraag naar een uitweg. Hij lijkt beheerst te worden door het noodlot. Het kwaad van de ongeremde technologie kan door geen mens gekeerd worden. De mens geeft er zich zelfs aan over en wordt er het slachtoffer van en verliest daarmee zijn vrijheid.

Marcuse neemt met deze onderdrukking van de mens geen genoegen. Hij interpreteert de Hegelse dialectiek als een revolutionaire. De mens zelf zal voor een ommekeer, een revolutie moeten zorgen. Hij richt zijn revolutionaire kritiek op economische en politieke machthebbers, een elite die wetenschap en technologie in dienst neemt om zijn macht te versterken. Marcuse's alternatieve toekomstvisie is die van de vrije mens, die zich verzet tegen elke macht en elke vorm van gezag. In die toekomst is de mens niet 
langer de ééndimensionale, de alleen maar werkende, arbeidende mens, de mens ook met een vaststaande onderdrukkende sexuele moraal, maar de mens die vrij en gelukkig is. Prestatie moet ruimte maken voor genot. Eros wordt bevrijd en macht maakt plaats voor zeggenschap. Op een revolutionaire manier moet deze visie in praxis worden omgezet. In een permanente omkering van de maatschappij wordt via de democratisering van elke vorm van samenleven de zelfbeschikking van iedereen tot leidraad. Met ander woorden de bestaande cultuurtrend moet worden doorbroken. De authenticiteit van elk mens moet in de praktijk van alle dag een kans krijgen. Op die manier komt er ruimte voor de bevrediging van het menselijk bestaan, voor levensgenieting en het uitleven van levensdriften, die nu maar al te zeer in de verdrukking zijn gekomen. Niet voor niets wordt 1968 dan ook wel verbonden met de seksuele revolutie.

\section{Een uitzonderlijke revolutie}

De studentenrevolte was een uitzonderlijke revolutie. Deze beweging vond niet in het centrum van het maatschappelijk leven plaats. Het revolutionair subject was niet de arme arbeidersklasse, zoals bij Marx. Neen, de studenten van ouders, die geld hadden, en die vanwege hun studie vooruitzichten hadden op een goede baan, namen geen genoegen met de maatschappij, met de ééndimensionale maatschappij van werken, van economie en technologie; ze wilden meer aandacht voor vernieuwing in zeggenschap - directe democratie! - en voor een nieuwe beleving van de seksualiteit. Die zou niet langer alleen op voortplanting en binnen het huwelijk moeten plaats hebben, maar zich in het botvieren van lusten moeten ontplooien in alle mogelijke andere richtingen. En in het culturele leven zou in plaats van de beheersing de verbeelding aan de macht moeten komen.

Veel te weinig wordt ingezien hoezeer deze culturele revolutie in verband staat met de technische ontwikkeling. Zonder een technologisch fundament zou de culturele revolutie niet hebben plaatsgevonden. Medische technologie maakte anticonceptie mogelijk, waardoor seksualiteit werd losgemaakt van de voortplanting. Een volgende stap was dat deze losmaking werd verheerlijkt in de vorm van alle mogelijke seksuele belevingen. Niet voor niets kwamen huwelijk en gezin sinds de jaren 1960 en 1970 dan ook ongekend onder druk te staan. Daarnaast zorgde aanvankelijk de TV - later versterkt door de computer en internet - ervoor dat culturen werden opengebroken. Technologie en economie zorgden samen voor een 
zielloos materialisme. In Nederland verdween de verzuiling - de inrichting van de maatschappij naar de verschillende levensovertuigingen. Bovendien ontstond er wereldwijd een cultureel relativisme en zelf een religieus relativisme. Niets verdiende meer zich met "waarheid" te verbinden. Dat betekende ondertussen dat een duidelijke cultuuroriëntatie verdween. Het geheel gaat meer lijken op een draaikolk waarin mensen worden meegesleurd en ook bedreigd. Voor die bedreiging is de technologie zeker zo verantwoordelijk als voor de beleefde bevrijding. Denk maar aan de wereldomspannende bedreiging die uitgaat van de kernbewapening en van natuurverwoesting en milieuschade en dientengevolge vandaag door klimaatwijzingen en het uitsterven van vele planten en diersoorten. Ondertussen heeft het geestloze materialisme gezorgd voor religieus ontheemde mensen met nog steeds enorme pretenties in wetenschap en technologie, maar ook in de beleving van hun vrijheid en genot.

\section{Geestelijke achtergrond}

Het lijkt er op dat we met 1968 met een discontinuïteit in de cultuurontwikkeling te maken hebben. Niets is minder waar. In 1968 komt meer aan de dag wat al lange tijd, ondergronds, in de Westerse cultuur doorwerkte. En na 1968 houdt de cultuurevolutie niet op. Die gaat ook vandaag nog ongehinderd door, zij het dat wel steeds meer tegenbewegingen zich laten gelden, zonder overigens de hoofdtrend van de cultuur te keren.

Om op dat proces een goed zicht te krijgen, is inzicht nodig in de culturele spanningen die in de Westerse cultuur alle lange tijd aanwezig zijn, maar die sinds 1968 verhevigd worden ervaren en beleefd, en soms zelfs revolutionair uitgedragen. Daarvoor oog krijgen, vraagt aandacht voor de religieuze uitwerking van de Verlichting in de Westerse cultuur.

\section{Wat is dialectiek van de cultuur?}

Wat wordt er met de dialectiek van onze cultuur bedoeld? De spanning tussen enerzijds enorme macht in wetenschap, economie en niet te vergeten technologie en anderzijds de menselijke vrijheid die er aan ten grondslag ligt, maar er ook door wordt bedreigd.

Dooyeweerd zag de oorsprong van de Westerse dialectiek in de pretentie van de zichzelf genoegzame mens, van de mens die autonoom is, van de mens zonder God. In het verlengde daarvan wordt de wereld aanvaard als een antropocentrische, gesloten wereld en de geschiedenis als een louter menselijke geschiedenis. Omdat in 
onze cultuur de openheid naar de transcendente God is dichtgeslagen, is de mens, in welke variaties dan ook, slechts of uiteindelijk alleen aangewezen op de diesseitige werkelijkheid. De Westerse mens tracht de idee van de zelfverheerlijkende autonomie waar te maken in de wetenschap en later te bevestigen in de techniek. De gedachte vat post dat mens en wereld door middel van de moderne techniek tot voltooiing gebracht kunnen worden. Deze ontwikkeling heeft machten opgeroepen die de spanningen in de wereld gigantisch groot maken. Het ideaal van ongekende materiële welvaart mag dan deels vervuld zijn, tevens is duidelijk geworden dat dit ten koste gaat van de menselijke vrijheid, van het leefmilieu, en dat wij ons met de welvaart op een vulkaan bevinden, die op uitbarsten staat. De Westerse cultuur is een cultuur die in zichzelf verdeeld is. De verabsoluteerde vrijheid komt op gespannen voet te staan met de verabsolutering van de wetenschappelijk-technische beheersing, en omgekeerd. Die spanning werkt zich in de geschiedenis uit.

\section{Twee verlichtingsidealen}

De Verlichting wordt gekenmerkt door twee idealen: het wetenschapsideaal en het vrijheidsideaal. Deze idealen hebben veel positiefs tot stand gebracht. Te denken valt aan de vele materiële ontwikkelingen op gebied van gezondheidszorg, werkgelegenheid, wetenschap en technologie en bevordering materiële welvaart. Ook de deelname in allerlei vormen van onderwijs is mee aan de Verlichting te danken. Toch lopen we met de radicalisering van de Verlichting momenteel vast. Dat komt omdat wetenschap en vrijheid steeds meer losgemaakt zijn van hun oorsprong en zodoende verabsoluteerd zijn. We krijgen te maken met de ontsporingen van het wetenschapsideaal en het vrijheidsideaal. Beide idealen missen een metafysische samenhang en een transcendente oorsprong. Het wetenschapsideaal verbindt zich met technologie en economie en zorgt voor een op economische groei gerichte ontwikkeling, die materieel veel resultaat brengt, maar in haar spoor vele ecologische en sociale problemen veroorzaakt. De ethiek van de huidige cultuur is ten principale - vanwege de keus voor de fundering in de Verlichting (alleen) - gefundeerd in wetenschappelijk-technische beheersing en economische groei enerzijds en anderzijds in een vrijheid die van geen verantwoordelijkheid, van geen orde en gezag wil weten.

Om wat meer zicht te krijgen op de ernst van de spanningen in de huidige cultuur zullen we meer aandacht moeten geven aan de consequenties van beide Verlichtingsidealen. Daarna zullen we aan- 
dacht geven aan een oplossingsrichting voor de geschetste problemen.

\subsection{Het vrijheidsideaal}

De individuele vrijheid, die door de Verlichting geprezen wordt, heeft in haar ongenormeerde vorm veel schade toegebracht aan een zinvol geordende samenleving. Vrijheid wordt in onze cultuur steeds meer een anarchistische vrijheid; vrijheid wordt losgemaakt van gezamenlijke, maatschappelijke vrijheid, van haar zedelijke grond en van haar zedelijke opdracht. Vrijheid wordt steeds meer gezien als vrijheid los van verantwoordelijkheid, en dan wordt ze inhoudsloos en dus leeg en tot een bedreiging. De gevolgen van de zestiger jaren uit de vorige eeuw met het aanhoudende verzet tegen traditie, gezag en waardenbinding hebben onze maatschappij in onbalans gebracht. De waarde van en achting voor de menselijke persoon lijdt daardoor schade. Ongemerkt heeft er een uitverkoop van de eigen cultuur plaats gehad, die zijn weerga niet kent. De heksenketel van het relativisme speelt nog velen parten. Sommigen spreken zelfs van de dictatuur van het relativisme. Vrijheid in de vorm van onverschilligheid en liederlijkheid constateren we overal. Huwelijk en gezin worden niet meer als dragende grond van een gezonde maatschappij aanvaard. Ondertussen zitten velen met deze trend in hun maag.

\subsection{Het wetenschappelijk-technisch beheersingsideaal}

Aan de Verlichting hebben we ook het wetenschappelijk-technisch beheersingsideaal te danken. Het is zelfs door het vrijheidsideaal opgeroepen. Maar tegelijk wordt de vrijheid er door bedreigd. Onder invloed van de begeerte om alles naar de hand van de mens te zetten en zo aan zich te onderwerpen, penetreert en richt de moderne techniek, die op de wetenschap gebaseerd is, heel de cultuur. De cultuur wordt daarmee een "technische cultuur". De techniek zet op alles een stempel en alles wordt van de techniek afhankelijk. In verbinding met de economie wordt de cultuur ééndimensionaal. Wetenschap en techniek en met haar de rationaliteit kunnen verwoestend worden, wanneer ze van hun wortels worden losgemaakt en het machenkönnen tot de enige maatstaf maken. Het eigenlijke probleem, waarvoor wij vandaag staan, is de blindheid van de rede voor de niet-materiële dimensie van de werkelijkheid. Dat heeft ernstige gevolgen.

Terwijl de mens denkt zijn cultuur met een grenzeloze ontwikkeling van techniek en economie veilig te kunnen stellen, is er de enorme 
dreiging dat datgene waarop het menselijk bestaan rust, kapot wordt gemaakt. De brutalisering van de huidige technische ontwikkeling bedreigt de duurzaamheid van de natuurlijke omgeving en van de biosfeer.

Vanwege de verabsolutering van het technische denken gaat er veel van de werkelijkheid verloren. Wat niet binnen het technische model past, wordt veronachtzaamd of vergeten. De werkelijkheid wordt als het ware gezien als een technisch geheel, dat wij door de techniek vervolgens kunnen verbeteren. Deze overspannen technische denkwijze vertaalt zich in een technisch wereldbeeld. Ze is een constructie van mensen en werkt als een cultuurparadigma. Het technische wereldbeeld heeft de ontwikkeling van de Westerse cultuur in toenemende mate gestempeld en stempelt ook de huidige globalisering. Het zijn vooral de technisch-economische machten die daarvan de drijfkrachten zijn en tegelijk ademen we allemaal de lucht van deze technische mentaliteit in. Aan deze heerszucht komen we door de hebzucht van het consumentisme allemaal tegemoet. De eerder genoemde ongeremde vrijheid - de andere pool van de Verlichting - wordt door het materialisme eerder versterkt dan geremd.

\subsection{Primaat van het wetenschappelijk-technische beheersingsideaal}

Dat het wetenschappelijk-technische beheersingsideaal het steeds weer wint van de andere pool van de culturele dialectiek, namelijk het vrijheidsideaal, komt omdat dit ideaal gebruik maakt van de objectieve cultuurmachten, die zich manifesteren in nieuwe wetenschappelijke en technische mogelijkheden, zoals systeemtheorie, informatica, computertechniek en genetische manipulatietechnieken. De economische machten versterken dat proces bovendien. Een cultuuromslag is, hoezeer de kritiek ook toeneemt, bijna onmogelijk. De oorzaak daarvan ligt vooral bij economische machten die geen maat weten te houden, en bij de massa als consument omdat die de bestaande hoofdstroom in de cultuur steeds weer bijvalt, omdat ze gelooft in en hoopt op nog meer zegeningen van wetenschap en techniek.

\section{Ernst huidige dialectiek}

Het is noodzakelijk te benadrukken dat in dit historisch proces de culturele dialectiek steeds ernstiger vormen aanneemt. De moderne techniek en het gebruik van haar mogelijkheden komen tot ongemene groei en nemen een despotisch karakter aan. Door de wetenschappelijk-technische beheersing van heel de wereld wordt niet 
alleen de mens in zijn vrijheid beknot, maar dreigen grondstoffenbronnen te worden uitgeput, de natuur te worden verwoest en het milieu te worden vervuild. Recent is er ook veel aandacht voor klimaatveranderingen. De ongeremde wetenschappelijk-technische dynamiek tergt natuurlijke, ecologische, energetische en sociale grenzen, waardoor botsingen ontstaan, die bij gebrek aan voldoende concrete uitwegen voor de spanningen ook razendsnel in conflicten kunnen uitmonden (Van der Wal \& Goudzwaard, 2006:223). In ontwikkelingslanden heersen door de invloed van de globaliserende technische en economische ontwikkeling meer dan eens gevoelens van politieke onmacht, gecombineerd met een aanhoudende economische tenachterstelling. Dat wordt meestal al snel als een rechtstreekse vernedering ervaren. Met andere woorden, de wetenschappelijk-technische cultuur van het Westen zet via de globalisering andere culturen onder druk. De dialectiek manifesteert zich gemakkelijk in een conflict tussen culturen, volkeren en naties. Er kunnen zich culturele rampen ontladen en er kunnen zich politieke catastrofes voordoen.

\section{Uitweg}

Over het algemeen valt men in onze cultuur het motief van de Verlichting nog steeds bij. Diepgaande kritiek op de "technologische cultuur" kan echter niet om de Verlichting heen. Kritiek op het te zeer wetenschappelijk-technisch omgaan met natuur en maatschappij betekent dat men niet kan volstaan met absolute vrijheid en absolute beheersingsmacht.

We ontnemen onszelf in de geest van de Verlichting maatstaven om tot goede afwegingen en oordelen te komen als we de geestelijke bronnen van de joods-christelijke traditie afzonderen en ons beperken tot de 200 jaar oude geestesbeweging van de Verlichting. Ik zeg duidelijk beperken. Dat is dus geen afscheid van de cultuur van de Verlichting, maar wel van de verabsolutering ervan. Inderdaad is de Verlichting een deel van de Europese vrijheidsgeschiedenis. Ze leeft echter meer en meer van vooronderstellingen en grondslagen die niet van de lange culturele geestes-geschiedenis afkomstig zijn. Als daar geen aandacht meer voor is, zal met het verdwijnen van een rijke geestelijke geschiedenis ook de Verlichting zelf in een heilloze crisis gestort worden. Op grote schaal kunnen we constateren dat het cultuurexperiment met alleen een fundament in de Verlichting is mislukt. We kunnen momenteel overal de tekenen daarvan zien: sociale ontbinding in een doorgeschoten individualisering en daarmee verbonden grenzeloze vrijheid en bedrei- 
ging van natuur en milieu zijn tekenen aan de wand. De Verlichtingscultuur zit in het moeras. Materieel steenrijk zijn maar geestelijk straatarm getuigt van metafysische lichtzinnigheid en ontbeert een hoognodig bezielend ideaal. Zonder zo'n geestelijk ideaal wordt de paradox steeds groter tussen een op consumentisme gerichte maatschappij en de noodzakelijke eis duurzaamheid te bevorderen. De gouden kalfvisie zal steeds meer teleurstellen. Verlichting dreigt om te slaan in verblinding.

\subsection{Verlichting van de Verlichting}

Om de geestesgeschiedenis van onze cultuur weer helemaal recht te doen, zullen we achter de Verlichting terug moeten gaan. Om de blijvende positieve betekenis van de Verlichting daarbij tegelijk te behouden, kunnen we ook zeggen dat we in onze cultuur een verlichting van de Verlichting nodig hebben. Erkenning van God als oorsprong en de mens als verantwoordelijk beeld van God, die een goddelijke roeping heeft om de werkelijkheid als schepping van God - ook door wetenschap en technologie - te ontsluiten, maakt de zin van wetenschap en techniek ondergeschikt aan de goddelijke zin van de geschiedenis: het koninkrijk van God. De cultuur kiest dan weer voor een religieus fundament met transcendente verankering omdat de religie van de materie als consequentie van de verabsoluteerde Verlichtingsidealen ons op nationaal, Europees en wereldniveau voor steeds grotere problemen plaatst. Religie en spiritualiteit blijken steeds meer nodig te zijn voor een duurzame samenleving. Vanuit de religie worden weer - lange tijd veronachtzaamde - fundamentele kwesties aan de orde gesteld. Wat is het wezen, de zin van het mensenleven, van de cultuur, van de technologie en van de economie? Vanuit deze fundamentele vragen, vanuit de religieuze wortels van de Europese cultuur, worden de lijnen doorgetrokken naar alle cultuurvormende sectoren.

Wat we onder invloed van het Christendom hebben geleerd, blijft zeer actueel: de werkelijkheid is geschapen werkelijkheid, naastenliefde en barmhartigheid, menselijke waardigheid, mensenrechten en mensenplichten, bescherming van het leven, gemeenschapszin, publieke gerechtigheid, sociale rechtvaardigheid, vrede in de maatschappelijke, onderlinge verhoudingen, de juiste balans tussen gezag en ontzag, vrijheid in verantwoordelijkheid, oriëntatie op de toekomst. Dus verantwoorde cultuurontwikkeling. We hebben geleerd dat de sterken moeten opkomen voor de zwakken, de gezonden voor de zieken, de jongeren voor de ouden en omgekeerd. We erkennen de betekenis van verscheidenheid in verantwoordelijk- 
heden en dat allen gelijk zijn voor de wet. En dat we een scheppingsmandaat hebben: in ons werk de schepping ontwikkelen en bewaren tegelijk. Cultuurwerk dus in dienst van al het leven. Gaan we deze weg van heroriëntatie niet, dan ontwortelen we steeds meer. We bouwen weliswaar torens van Babel, maar op drijfzand.

Kortom, op grote schaal kunnen we constateren dat het cultuurexperiment met alleen een fundament in de Verlichting is mislukt hoeveel we er overigens ook aan te danken hebben. Een wending in de cultuur is vereist waardoor spanningen en dreigingen afnemen. Een vaste basisoriëntatie is nodig - of anders gezegd: een metahistorisch en moreel kompas. Dat leidt tot vernieuwing van de cultuur en daarmee van haar politieke, sociale, economische en culturele projecten.

Die nieuwe cultuurrichting is de richting van de scheppingsdynamiek, de dynamiek van de gerechtigheid, die de mens door zijn zonde perverteert. De cultuurdialectiek parasiteert op de scheppingsdynamiek, maar kan die niet ongedaan maken. In Christus is immers die dynamiek der gerechtigheid hersteld. Daarin ligt het bevrijdende perspectief van de cultuur. Van de mens wordt omkering en heroriëntatie gevraagd; dat is afstemming op die dynamiek der gerechtigheid; in persoonlijke en gemeenschappelijke verantwoordelijkheid; in alle levensuitingen: individueel, gemeenschappelijk en cultureel. Vereist is een noodzakelijke paradigmawisseling van de "technologische cultuur".

\section{Kuhn's paradigmatheorie}

Om die paradigmawisseling enigszins helderder te maken, geef ik ter toelichting als voorbeeld Thomas Kuhn's paradigmatheorie voor de ontwikkeling van de wetenschap. Kuhn heeft vanuit de feitelijke ontwikkeling van de wetenschap duidelijk gemaakt dat wetenschappelijke theorieën uiteindelijk in sociologische, psychologische, economische en zelfs religieuze termen verklaard kunnen worden. Daarmee wordt niet alleen de continue groei van wetenschappelijke kennis verklaard, maar vooral ook de sprongsgewijze ontwikkeling. De continue ontwikkeling van de wetenschap vertoont stabiliteit en overeenstemming tussen wetenschappers. In geval van een crisis in de wetenschapsontwikkeling leidt dit tot wisseling van het raamwerk, het paradigma, waarbinnen de wetenschap wordt ontwikkeld. Pas de totstandkoming van een nieuw paradigma kan de breuk herstellen en een nieuwe periode van normale wetenschap inluiden. Ondertussen zijn met zo 'n paradigmawisseling de waarheidsaanspraken van de wetenschap behoorlijk gerelativeerd (Kuhn, 1962). 
Kuhn leert dat er in crises in wetenschappelijke theorievorming ineens grote en fundamentele vragen worden gesteld. Het oude wetenschapsgeloof schudt op zijn fundamenten. Oude vanzelfsprekendheden gaan op de helling. De gemeenschap van wetenschappers kalft af. Unanimiteit brokkelt af. Waarden consensus verdwijnt. De tacit knowledge van gelijkgezinden wankelt. Kortom, het oude paradigma heeft zijn beste tijd gehad. Een nieuwe ontwikkeling breekt baan (Koningsveld, 2006:110 e.v.).

Zou Kuhn's visie op paradigmawisseling in de wetenschap een analogie kunnen vormen voor een noodzakelijke verandering in het cultuurparadigma? Een analogie leert ons iets, maar heeft ook haar beperkingen. Zo is wetenschap slechts een tak of onderdeel van de cultuur. De cultuur omvat zoveel meer dan wetenschap. Maar juist omdat onze cultuur meer en meer als "technologische cultuur" of "wétenschappelijk-technische cultuur" wordt gezien, geeft dat aanleiding om ons toch door Kuhn te laten inspireren.

\section{Transformatie van de "technologische cultuur"}

Daarom: zou zich zoiets - relativering van het bestaande cultuurparadigma en transformatie ervan - ook niet in de huidige cultuurontwikkeling kunnen voordoen? Binnen het overheersend cultuurparadigma van het Westen hebben we met veel problemen te maken. Deze problemen trachten we momenteel meestal op te lossen met dezelfde middelen en methoden die zij hebben opgeroepen. De oplossingen blijken, vooral met steun van de economie en de politiek, onderdeel van de problemen van onze cultuur te zijn. Zo langzamerhand leren we inzien dat dit niet langer kan. Is de kans aanwezig dat we in de crisis een weg vinden naar een nieuwe cultuurfase waarin de problemen van de "technologische cultuur" echt kunnen worden terug gedrongen?

Een culturele revolutie of culturele omslag naar analogie van een wetenschappelijke revolutie zal gepaard gaan met spannende discussies, die uiteindelijk teruggaan op wat men gelooft en voor waar houdt. Hier komt de rol van de religie om de hoek kijken. Vanuit die religie of religies worden verschillende vormen van cultuurkritiek, i.c. technologiekritiek geleverd. De uitdaging is om met een ander cultuurparadigma te komen dat de cultuurdialectiek vermindert en dat de bestaande problemen en dreigingen beperkt of zelfs oplost. Dat is niet eenvoudig, want vertegenwoordigers van het oude cultuurmodel geven niet snel op. Met een zekere verbetenheid houden ze er aan vast. Dat zijn tegenkrachten van economische, politieke en culturele aard. Maar tegelijk wordt naarmate de bestaande ontwik- 
keling zich doorzet, de zwakte ervan steeds duidelijker. Zien we dat niet in de toenemende wereldbedreigende gevolgen van het huidige wetenschappelijk-technisch-economisch denken?

\subsection{Het conflict tussen industriële en biologische landbouw}

Toch, er zijn mogelijkheden. Een concreet en actueel voorbeeld van cultuurverandering is de strijd die de biologische en ecologische landbouw - al of niet met succes en al of niet met afdoende argumenten - voert tegen de industriële landbouw. Die industriële landbouw roept steeds meer problemen op. Aandacht daarvoor en oplossingen ervan krijgen meer en meer kansen, temeer als steeds meer tegenstanders van de industriële landbouw en meer en meer medestanders van de biologische landbouw aan het woord komen en binnen de nog vage omtrekken van een nieuw paradigma ook meer successen worden geboekt. Omgekeerd zie je verdedigers van de industriële landbouw pleiten voor ecologisering van de landbouw. Beide ontwikkelingen geven aan dat bestaande groeiende problemen onder ogen worden gezien en dat nagegaan wordt hoe nieuwe, duurzame wegen kunnen worden in geslagen (Simons, 2007:63, 240 e.v., 374 e.v.).

\subsection{Cultuuromslag}

Een dergelijke omslag zou de hele "technologische cultuur" moeten betreffen. We zien dat vanwege de opdoemende problemen politiek en economie al meer belangstelling krijgen voor cultuuralternatieven en duurzame ontwikkeling en maatschappelijk verantwoord ondernemen. Het sociaal-economische klimaat wordt gunstiger voor drastische veranderingen. Zo geven recente rapporten vanuit het bedrijfsleven richting de politiek aan dat er meer aan het milieuvraagstuk en de klimaatwijziging moet worden gedaan. Maar ook een recent VN-rapport over het klimaat van een wereldwijde samenwerking van 2500 wetenschappers, die de mensen met hun techniek, economie en consumptie als de belangrijkste oorzaak aanwijzen van de grote uitstoot van broeikasgassen, met alle risico's van dien, werkt als katalysator voor nieuwe cultuurontwikkelingen.

Aandacht voor klimaatswijziging, zeespiegelstijging, verschuiven van klimaatgordels, verstoring van ecologische systemen, verlies van biodiversiteit, nieuwe tropische ziekten, enzovoort doen een appèl op een verandering in het cultuurethos. Clinton's en Al Gore's acties evenzo. De jarenlange invloed van Greenpeace moet eveneens niet worden onderschat. Meer en meer gaan de ogen open voor een ander cultuurparadigma. Meer en meer ziet men in dat de 
moderne maatschappij met haar patronen van produceren, beheersen en consumeren inherent, en niet toevallig, onduurzaam is (Van de Wal \& Goudzwaard, 2006:8 e.v.). Het bestaande cultuurpatroon wordt door dat alles ondermijnd. En naarmate de politiek echt werk maakt van duurzaamheid, bijvoorbeeld door de introductie van het voorzorgsbeginsel, en duurzaamheid dus niet tot een toverwoord of mythe laat verworden, roept de heersende cultuur steeds meer twijfel op. De politiek kan zo positief meewerken aan een verandering in de cultuurgezindheid van velen. Als daarenboven ook de consument gaat inzien aan welke gevaren hij bij nieuwe benaderingen ontsnapt en dat de kwaliteit van zijn leven, zijn welzijn, wordt bevorderd, zijn de voorwaarden gunstig voor een cultuurcrisis. Een hoognodige cultuuromslag ligt in het verschiet, met meer aandacht voor het leven van toekomstige generaties en voor de rijkdom van talrijke, gevarieerde medeschepselen, dus voor echte duurzaamheid. Met meer aandacht ook voor gerechtigheid tegenover de ongerechtigheid van de huidige globaliserende ontwikkeling.

Van belang is dus dat de na- of post-industriële cultuur de problemen en dreigingen van de industriële cultuur vermindert en helpt oplossen. Dat zal een leerproces van kleine en grote stappen moeten zijn. Een proces waarin aan het woord komt wat vergeten werd of dreigde vergeten te worden. Ik denk dat de verhoogde belangstelling voor religies op dit moment hier ook álles mee te maken heeft. Vanuit die religies worden weer, lange tijd veronachtzaamd, fundamentele kwesties aan de orde gesteld. Wat is het wezen, de zin van het mensenleven, van de cultuur, van de technologie en van de economie? Vanuit deze fundamentele vragen vanuit de religieuze wortels van culturen - worden de lijnen doorgetrokken naar alle cultuurvormende sectoren. Naar analogie van Kuhn's woordgebruik kunnen we hier spreken van een gestalt switch, een ommekeer of revolutie. Het gaat om een sprong. Terecht, want het is time to turn. Een wending in de cultuur is vereist waardoor spanningen en dreigingen afnemen.

\subsection{Inhoud nieuw cultuurparadigma}

En hoe zou het nieuwe cultuurparadigma er dan uit moeten zien? Wat is de essentie ervan? Het moet wezenlijk van het voorgaande verschillen en toch het oude opnemen in een transformatieproces. In het oude cultuurparadigma wordt de natuur als levenloos gezien en binnen dat kader uitgebuit door onbegrensde manipulatie. Daarom: werden tot voor kort in het technisch paradigma, natuur, mens, milieu, planten en dieren bekeken vanuit een technische blik, 
het zogenaamde machinemodel, nu zal de bescherming van het léven bij cultuurvorming het allesbeheersend gezichtspunt moeten zijn. Wetenschap en techniek en economie zullen het léven in alle gevarieerdheid en vormenrijkdom niet mogen vernietigen, maar er juist van in dienst moeten staan. Technologie en economie zullen in dit perspectief meer aan hun zin kunnen beantwoorden. Het tuinmodel is daarvoor passend. Binnen dat wordt het leven niet bedreigd, maar verrijkt. Wetenschap en technologie in dienst van het leven, persoonlijk en gemeenschap, en met bescherming van planten en dieren en de biosfeer, geeft een wending in vele aandachtsgebieden van de cultuur.

De ontsluiting van de schepping komt in het perspectief van de levende tuinstad te staan. In dat perspectief is er zorg voor milieu en natuur. Behoud van het leven en welzijn gaan boven groei van materiële welvaart.

Het oriëntatiekader in de cultuur met leven en liefde als grondcategorieën en het bevorderen en versterken van recht en gerechtigheid als opdracht, heeft aandacht voor boven-subjectieve normatieve grenzen. Hierdoor nemen cultuurspanningen af en wordt een evenwichtige, duurzame, vreedzame en ook rijk gevarieerde ontwikkeling mogelijk. Maat weten te houden, zal de cultuurspanningen en dreigingen doen afnemen. Een meer duurzame, rechtvaardige, globaliserende ontwikkeling is mogelijk, wereldproblemen en wereldomvattende dreigingen worden terug gedrongen. Dat is de inhoud van de strijd om de juiste richting voor de globaliserende wereldcultuur, waarvan de oorsprong de Westerse cultuur is.

\section{Geraadpleegde bronne}

BARBOUR, I. 1990. Religion in an age of science. San Francisco: Harper.

DOOYEWEERD, H. 1959. Vernieuwing en bezinning: om het reformatorisch grondmotief. Zutphen: Van den Brink.

GRAY, J. 2007. Blackmass: apocalyptic religion and the death of Utopia. London: Penguin.

HABERMAS, J. 2005. Zwischen Naturalismus und Religion. Frankfurt am Main: Suhrkamp.

HITTINGER, R. 1995. Christopher Dawsons's insights: can a culture survive the loss of its religious roots? (In Collens, F.T., ed. Christianity and Western civilization. San Francisco: Ignatius. p. 115-126.)

HUNTINGTON, S. 1996. The clash of civilizations and the remaking of worldorder. New York: Simon \& Schuster.

KONINGSVELD, H. 2006. Het verschijnsel wetenschap. Amsterdam: Boom.

KUHN, T.S. 1962. The structure of scientific revolutions. Chicago: University of Chicago Press. 
KÜNG, H. 1997. Weltethos für Weltpolitik und Weltwirtschaft. München: Piper Verlag.

MARCUSE, H. 1962. Eros and civilization. New York: Vintage.

MARCUSE, H. 1964. One-dimensional man. Boston: Beacon.

NEWMAN, J. 1997. Religion and technology: a study in the philosophy of culture. London: Westport.

NOBLE, D.F. 1997. The religion of technology: the divinity of man and the spirit of invention. New York: Knopf.

OPSCHOOR, J.B. 2007. "Wealth of nations" or a "common future": religionbased responses to unsustainability and globalisation. (In Klein Goldewijk, B., ed. Religion, international relations and development cooperation. Wageningen: Academic Publishers. p. 247-281.)

RATZINGER, J. 2005. Waarden in tijd van ommekeer. Antwerpen: Lannoo.

SCHUURMAN, E. 2004. Geloven in wetenschap en techniek: hoop voor de toekomst. 2e dr. Amsterdam: Buijten \& Schipperheijn.

SCHUURMAN, E. 2005. The technological world picture and an ethics of responsibility. Sioux Centre: Dordt College.

SCHUURMAN, E. 2009. The challenge of Islam's critique of technology. (In Goheen, W. \& Glanville, E.G., eds. The gospel and globalization. Vancouver: Regent College Publishing. p. 199-217.)

SIMONS P. 2007. Tilling the good earth: the impact of technicism and economism on agriculture. Potchefstroom: North West University Press.

STÖCKLEIN, A. \& RASSEM, M., herausg. 1990. Technik und Religion. Düsseldorf: VDI Verlag.

SWEARINGEN, J.C. 2007. Beyond paradise: technology and the kingdom of God. Oregon: Wipf \& Stock.

VAN DER WAL, K. \& GOUDZWAARD, B. 2006. Van grenzen weten: aanzetten tot een nieuw denken over duurzaamheid. Budel: Damon.

VAN DER WALT, B.J. 2007. Transforming power: challenging contemporary secular society. Potchefstroom: Institute for Contemporary Christianity in Africa.

ZUIDEMA, S.U. 1970. De revolutionaire maatschappijkritiek van Herbert Marcuse. Amsterdam: Buijten \& Schipperheijn.

\section{Kernbegrippen:}

culturele paradigmaschuif

culturele revolutie

culturele transformatie

technologie

Verlichting

\section{Key concepts:}

cultural paradigmshift

cultural revolution

cultural transformation

Enlightenment

technology 